\title{
BMJ Open Quality Reducing bed occupancy and length of stay on a functional older adults' psychiatric ward
}

\author{
Azad Cadinouche, Auzewell Chitewe, Kehkashan Khan, Sylvester Lamin, \\ Kajanesh Ratneswaran, Amar Shah, Marco Aurelio
}

To cite: Cadinouche A, Chitewe A, Khan $\mathrm{K}$, et al. Reducing bed occupancy and length of stay on a functional older adults' psychiatric ward.BMJ Open Quality 2017;6:e000160. doi:10.1136/ bmjoq-2017-000160

- Additional material is published online only. To view please visit the journal online (http://dx.doi.org/10.1136/ bmjoq-2017-000160).

Received 6 July 2017 Revised 4 October 2017 Accepted 5 October 2017

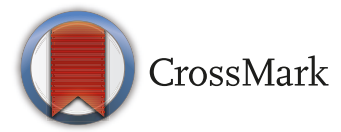

East London NHS Foundation Trust, London, UK

Correspondence to Marco Aurelio; marco.aurelio@elft.nhs.uk

\section{ABSTRACT}

A quality improvement project was initiated on Ivory ward, a functional older adult psychiatric inpatient ward at Newham Centre for Mental Health, part of the East London NHS Foundation Trust. The project was started by staff on the ward after it had come to their attention that their ward had the highest bed occupancy and length of stay across similar wards in the trust. The mean bed occupancy in the 9 months before the project started was $87.7 \%$. The mean length of stay on the ward in the 9 months before the project started was 70 days. The team used the model for improvement, which is the trust's methodology of choice for quality improvement projects, to reduce bed occupancy and length of stay. The focus was on running small-scale tests of change to see whether these could lead to improvement. These change ideas were refined, scaled up or discontinued as appropriate to help achieve the aim. The project's aim was to promote quality of care by reducing patient length of stay on Ivory ward to 45 days and bed occupancy to $\leq 70 \%$ or by 1 January 2016 . The project team managed to reduce bed occupancy to $58 \%$ and length of stay to an average of 35 days.

\section{PROBLEM}

\section{The problem}

Prior to instigating our proposed intervention, we identified Newham's older adult ward (Ivory ward) had higher bed occupancy $(90 \%)$ and longer length of stay (LoS) $(70$ days) compared with other older adult psychiatric units in the trust.

\section{The service}

Ivory ward is a 13-bedded functional older adult ward in Newham, East London. The ward falls under the Mental Health Care of Older People directorate at East London NHS Foundation Trust.

The aim

To reduce the average inpatient LoS on Ivory ward to 45 days and bed occupancy to $<70 \%$ by 1 January 2016 . An LoS of $<45$ days was chosen as it was the lower figure of the trust's older adults services LoS range (45-60 days). A bed occupancy of $70 \%$ was chosen to align it with the trust's average for older adults functional wards of $<80 \%$. This was a deliberate stretch target to really challenge the project team and see what was achievable.

\section{BACKGROUND}

Evidence suggests that very high bed occupancy negatively impacts the quality and safety of inpatient care. The problem of unnecessarily prolonged hospital admissions can adversely affect patient care, lead to higher incidences of violence and aggression, distract staff from direct patient care and distress service users who have to go on unplanned leave or to other units to ease bed pressure on the wards. ${ }^{1}$

The Royal College of Psychiatrists' recommended level of occupancy is $85 \%$ and levels $10 \%$ above this recommendation are associated with violent incidents on inpatient wards. $^{2}$

High bed occupancy and non-availability of beds cause delays in admission, which in turn result in

- patients becoming more distressed and unwell, leaving them more likely to need long-term care; ${ }^{3}$

- high level of out-of-area patients which are both costly and can have a negative impact on patient well-being, resulting in higher levels of suicide; ${ }^{4}$

- reduced availability of functioning clinical space to admit new patients, limiting effective clinical care and support current patients. ${ }^{5}$

\section{BASELINE MEASUREMENT}

Prior to instigating our proposed intervention, we identified Newham's older adult ward (Ivory ward) had higher bed occupancy (90\%) and longer LoS (70 days) compared with other older adult psychiatric units in the trust.

We therefore agreed on the following measures for the project: 
1. Bed occupancy (outcome measure): Presented as a percentage on a Shewhart control chart for attribute classification data (p-chart). The numerator is the number of occupied beds at 07:00 hours (excluding patients on leave and patients from other wards or other trusts). The denominator is the total number of beds on the ward $(n=13)$. The rationale was that the project team believed the most accurate source of this information was the daily bed state reports that were sent out each morning by the Duty Senior Nurse . Due to the number of these reports produced, the team decided to use a weekly snapshot taken from the Saturday report. The team also believed that the data pulled out on the Saturday morning was the best representation of how their system was performing for that week in terms of discharges and number of patients on leave from the ward. The team did not have the capacity to collate this data on a daily basis.

2. LoS (outcome measure): Presented as days on a Shewhart control chart for variables data (individuals chart). LoS defined as discharge date minus admission date. This included periods of leave before discharge. LoS was only calculated when someone was discharged. This data was extracted from the data warehouse which was populated from the Electronic Patient Record system.

3. Discharge planning huddles (process measure): Number of discharge planning huddles completed each week. During the huddle, the nurse coordinating the shift recorded on an A3 size flip-chart paper on the wall that a huddle took place by crossing off the corresponding date.

4. Completion of discharge planning checklist (process measure): Audit of case notes carried out by senior staff during supervision with named nurses. This was to determine whether all patient files had a copy of the fully completed discharge planning checklist attached.

5. Admissions to the ward (balancing): Number of admissions to the ward each week. This data was taken from the trust reporting system.

Readmissions were initially considered as a balancing measure for the project. However initial data collection highlighted that the rate was negligible and data collection was disbanded. Deaths on the ward were not tracked as part of this project.

At fortnightly project team meetings, the team either looked at the control charts displaying these data or a dashboard which showed a snapshot of the current bed occupancy. This helped inform the 'study' part of discussing Plan, Do, Study, Act (PDSA) cycles and the impact of change ideas that were being planned or tested.

\section{DESIGN}

For the life of the project, the membership of the project team included staff from the ward (nurses, occupational therapists and doctors) and community (clinical lead, service lead and social worker). Community staff were important as responsibility of care post discharge lies here. The team also had the support of an improvement adviser from the central quality improvement team.

The team adopted the Institute for Health Care Improvement model for improvement to allow them to develop and test ideas. Ideas were tested using iterative PDSA cycles. This approach allowed the team to develop small-scale test of change, test them, learn from what happened and then make modifications. Using this model, the team developed and tested a range of interventions in the following order, including

- Checklist for inpatient pathway: Checklist of tasks needing completion at different stages along the care pathway after admission.

- Discharge planning checklist: Creation of a swim-lane flow chart to highlight tasks and decisions that would determine patient discharge location and tasks needed for each of these options to reduce unnecessarily long LoS.

- Setting an 'expected discharge date': Setting an expected discharge date 45 days from the date each patient was admitted and adding it to the discharge checklist. The team's hypothesis was that this would assist in planning for discharge at admission.

- Visual display of discharge barriers: Creation of a table used to display tasks or barriers related to each patient's discharge plan. This was populated from discussions in the weekly ward rounds and during the discharge planning huddles. At each huddle, the dashboard was projected on a screen and updated in real time. New tasks were written in red, task in progress in orange and completed tasks deleted. The dashboard was stored in a shared drive accessible to both inpatient and community staff.

- Discharge planning huddles: The team tested $30 \mathrm{~min}$ discharge planning huddles attended by multidisciplinary ward and community staff 3 days a week to talk through discharge plans and actions for each patient. The hypothesis was that by having regular brief discussions instead of just the weekly ward round decisions about patient care would be made more frequently and barriers to early discharge overcome by multidisciplinary collaboration and coordination. See online supplementary material for PDSA ramp describing the order of the interventions.

The team met on a fortnightly basis to discuss progress and look at the data being collected in control charts. This helped inform the 'study' part of the PDSA cycle and make decisions about the success of an intervention, if a test should be continued or abandoned and what modifications might be required for the next testing cycle. 


\section{STRATEGY}

Using the model for improvement, and a PDSA approach to developing and testing changes, the team was able to learn from and refine interventions.

As described above, the team tested a number of change ideas. These had mixed success, with the team feeling that more could be done. Overwhelmingly the team's theory was around communication of discharge issues and the opportunity to come together to speed up decision-making. As such the discharge planning huddle was the main change idea that was tested. It is important to note that many of the other change ideas tested were used to structure the huddle discussion.

\section{Discharge planning huddles: social worker involvement}

The team tested having a social worker present in the discharge planning huddles. This was introduced into the huddles after it was identified that some of the frequently incomplete tasks were to do with assessments and funding applications for accommodation.

\section{Discharge planning huddles: Rapid Response Team involvement}

The team also tested having a member of the Rapid Response Team present in fortnightly discharge planning huddles. The Rapid Response Team is a virtual ward that can deliver physical health interventions at home instead of an acute ward.

\section{Discharge planning huddle: community representation}

Community teams were invited to the huddle as some of the decisions required involved their input. They sent representatives to the huddles and took away tasks for their team or care coordinators.

\section{Discharge planning huddles: huddle structure}

With a multidisciplinary group of people coming together, the team felt that it was important to introduce structure into the huddles to ensure they were completed within $30 \mathrm{~min}$. The visual display of discharge barriers was projected onto a large screen in the nurse's office. This table evolved over time as it became apparent information pertaining to patients' social and financial position was often required to speed up discharge see online supplementary file.

\section{RESULTS}

The combination of interventions created a reduction in the bed occupancy and LoS as set out at the start of the project. At the end of 1 year,

- Bed occupancy was reduced to $58 \%$, representing a $34 \%$ reduction over the project duration (see supplementary file 2);

- LoS was reduced to 35 days, representing a $46 \%$ reduction over the project duration (see supplementary file 3$)$.

Looking at the data, it can be noted that introducing discharge huddles and then later social workers to the huddle seem to have had an effect on reducing LoS and bed occupancy.

\section{LESSONS AND LIMITATIONS \\ Lessons}

- With an older adult population, there are complex medical and social needs that must be addressed to facilitate a safe and efficient discharge. Thus it was important to work together with partners from both inside and outside the organisation including social and community care.

- The huddle needed a designated lead to delegate tasks. The 'huddle' discussions led to new or outstanding tasks being highlighted for action; however, without delegation to specific individuals it had led to these tasks being delayed. As such we believe a named individual would improve its efficiency and ability to chase the progress of these tasks.

- The huddle table was only used at the huddle; however, the information it contained could have been a central focus for nurses handovers.

\section{Limitations}

- Lack of data around the number of discharge huddles held weekly and the completeness of the discharge planning checklist. This was recorded on paper but not electronically on time-series graphs. Consequently, it is difficult to fully accurately assess the impact of these and, if required, fully understand how to scale and spread the idea to other wards if necessary.

- Lack of consideration given to qualitative feedback from staff and/or patients around how the ward environment might have changed.

- Applied to older adult ward only at Newham Centre for Mental Health and not at other sites.

- No comparison to general adult inpatient LoS or bed occupancy.

- At the time the trust had no means of systematically recording PDSA cycles, so it is likely some learning was not captured effectively.

\section{CONCLUSION}

Overall, data collection has shown sustainable results throughout the project.

The findings from this project correspond with findings on factors that have an impact on LoS which were tackled by the change ideas tested in this project. For instance, a study by Jacobs $e t a t^{6}$ identified three main predictors to increased LoS: socio-demographic characteristics of the patient, clinical characteristics (eg, comorbidities) and type of hospital. By taking a multidisciplinary approach to tackling social issues, physical health conditions and promoting care outside of the older people's mental health ward, this project team was able to effectively reduce the impact of these predictors and reduce LoS and bed occupancy. In addition, the role of intermediate care as part of a seamless service provision is seen as a 
key component to reducing delayed discharge in older people's mental healthcare services. ${ }^{7}$

Following a period of monitoring for the sustainability of the change, the project has now been closed and is monitored via quality control. Changes that have been adopted as standard work practices include discharge planning huddles, checklist for inpatient pathways, discharge planning checklist, setting expected discharge dates and visual display of barriers. The team continues to review the data in management meetings via the trust quality and performance dashboard system, which shows occupancy and LoS over time.

Acknowledgements Many thanks to the staff of Ivory ward and Michael Marin who assisted with data collection.

Competing interests None declared.

Ethics approval This work met criteria and East London NHS Foundation Trust's policies for operational improvement activities exempt from ethics review.

Provenance and peer review Not commissioned; externally peer reviewed.

Open Access This is an Open Access article distributed in accordance with the Creative Commons Attribution Non Commercial (CC BY-NC 4.0) license, which permits others to distribute, remix, adapt, build upon this work non-commercially, and license their derivative works on different terms, provided the original work is properly cited and the use is non-commercial. See: http://creativecommons.org/ licenses/by-nc/4.0/
(C) Published by the BMJ Publishing Group Limited. For permission to use (where not already granted under a licence) please go to http://www.bmj.com/company/ products-services/rights-and-licensing/

\section{REFERENCES}

1. Smith $S$, Chakraborty N. Reasons for prolonged admissions on acute adult psychiatry wards. Prog Neurol Psychiatry 2012;16:28-31.

2. Royal College of Psychiatrists. Do the right thing: how to judge a good ward. Ten standards for adult in-patient mental healthcare, 2011. http://www.rcpsych.ac.uk/files/pdfversion/OP79.pdf (accessed 4 Oct 2016).

3. McNicoll A. (2015) Sending acutely ill mental health patients out of area'increases post-discharge suicide risk: Community Care. http:// www.communitycare.co. uk/2 015/0 7/2 2/s en di ng -ac ut ely -ill-mental-h ealt $h-p$ atie nts- area -i ncreas es- $p$ ost- disc ha rg esuicide-risk/ (accessed 4 Oct 2016).

4. Miani C, Ball S, Pitchforth E, et al. Organisational interventions to reduce length of stay in hospital: a rapid evidence assessment. Health Services and Delivery Research 2014;2:1-178.

5. Royal College of Psychiatrists. Looking ahead-future development of UK mental health services: recommendations from a royal college of psychiatrists' enquiry (Occasional Paper OP75): Royal college of psychiatrists, 2010.

6. Jacobs R, Gutacker N, Mason A, et al. Determinants of hospital length of stay for people with serious mental illness in England and implications for payment systems: a regression analysis. BMC Health Serv Res 2015;15:439.

7. Paton JM, Fahy MA, Livingston GA. Delayed discharge-a solvable problem? The place of intermediate care in mental health care of older people. Aging Ment Health 2004;8:34-9. 